\title{
Quality of Root Canal Obturation Performed by Senior Undergraduate Dental Students
}

\author{
Sundahnath Nagaraja \\ Saveetha Dental College and Hospitals, Chennai, India
}

\begin{tabular}{l} 
Article Info \\
\hline Article history: \\
Received Jun 25, 2015 \\
Revised Aug 20, 2015 \\
Accepted Aug 30, 2015 \\
\hline Keyword: \\
Dental Radiography \\
Endodontics \\
Molar \\
Periapical radiograph \\
Root Canal Obturation
\end{tabular}

\section{Article Info}

Article history:

Revised Aug 20, 2015

Keyword:

Dental Radiography

Periapical radiograph

Root Canal Obturation

\begin{abstract}
The aim of the present study was to assess the quality of canal obturation performed by undergraduate denal students at Saveetha Dental College and Hospitals, Chennai. Records of 200 endodontically treated teeth from patients who were visited by undergraduate students between months of November 2014 to May 2015. Periapical radiographs of all treated teeth were assessed in terms of canal obturation quality (adequate density and length). Forty-five percent of teeth fulfilled the criteria of an acceptable root canal obturation. Adequate length and density of root filling was found in $89 \%$ and $34 \%$ of teeth, respectively. There was a significant difference between maxillary and mandibular teeth regarding the length of root canal obturation. A significant difference was observed between molars and other tooth types. The frequency of root canals with an acceptable filling was significantly greater in the anterior teeth compared to premolars or molars. The technical quality of root canal treatment performed by undergraduate dental students was found to be less than ideal.
\end{abstract}

Copyright (c) 2015 Institute of Advanced Engineering and Science. All rights reserved.

\section{Corresponding Author:}

Sundahnath Nagaraja,

Saveetha Dental College and Hospitals, Chennai, India

Email: dr.sundahnath@yahoo.com

\section{INTRODUCTION}

Preservation of the natural dentition has become more popular in the society [1]. Therefore, endodontic therapy is becoming an increasingly routine part of general dental practice [2]. Success of root canal treatment has been reported to be 53-94\% [3],[4]. The methods for assessment of endodontic treatment outcome are mostly based on radiographic evaluation only [5]-[7], combination of radiographic and clinical evaluation [8]-[10] or histological examination, in case of treatment failures [11],[12]. The quality of root canal treatment performed by general practitioners in different populations has also been extensively investigated in many studies, the results of which have shown high percentage of inadequate root canal treatment [7],[13]-[15]. The reasons are complex and may be related to the different endodontic teaching methods at dental schools [16]. Some of the problems in endodontic teaching may be attributed to limited time allocated to endodontics, poor staff-to-student ratios and the fact that many endodontists have not taken the teaching skills [17]. Students are taught endodontics from $3^{\text {rd }}$ year onwards till internship, at Saveetha Dental College and Hospitals, Chennai are expected to perform endodontic treatment on a variety of teeth belonging to the patients diagnosed to require root canal treatment. The aim of this observational study was to evaluate the technical quality of root canal obturation using radiographs of teeth treated by $3^{\text {rd }}$ year till interns undergraduate dental students at Saveetha Dental College and Hospitals, Chennai.

\section{RESEARCH METHOD}

Records of 200 patients, who had received endodontic treatment by $3^{\text {rd }}$ year till intern undergraduate students at Saveetha Dental College and Hospitals, Chennai from 2014 November till 2015 May, were 
selected and evaluated. Records that did not include preand post-operative periapical radiographs or those with poor radiographic quality besides the records of patients with incomplete endodontic treatment were excluded. The final sample consisted of 200 documents of endodontically treated teeth. Among these, 61 were anterior teeth while 47 and 92 teeth were premolars and molars, respectively. An aseptic technique with rubber dam isolation had been applied in all the cases and working lengths was determined by means of radiographs. All the teeth had been instrumented with passive step-back technique using stainless steel Kfiles with 0.02 taper and irrigated with $2.5 \%$ sodium hypochlorite solution. Root fillings had been carried out with lateral compaction technique using gutta-percha. All the teeth had been temporarily filled and referred for permanent restoration. All the treatment steps were conducted under the supervision of teaching staff. Evaluation of the technical quality of root canal treatment was based on the immediate postoperative RVG of each case. The final RVG were examined by two independent investigators using with a few selected cases which were not included in the study [16]. An evaluation form was designed to record the information gathered from the immediate postoperative radiographs. The method of viewing the radiographs was standardized using RVG. The results were compared and a final result was concluded. Each root was scored individually and the tooth was considered as a unit. In multi-rooted teeth, the highest score of all the roots was attributed to the tooth and ultimately, failure of one root was considered the failure of the tooth as a whole. The quality of endodontic treatment was determined by the length of root canal obturation in relation to the radiographic apex and also the density of the obturation based on the presence of voids as shown in Table 1. Meanwhile, Table 2 shows the distribution of teeth in maxillary and mandibular arches. Hence, Table 3 provides information about overall quality, length, and density of root canal filling.

Table 1. Criteria for assestment of radiographic quality of root canal filling

\begin{tabular}{ccc}
\hline Parameter & Criteria & Definition \\
\hline $\begin{array}{c}\text { density of root canal } \\
\text { filling quality }\end{array}$ & Adequate & $\begin{array}{c}\text { No voids present in the root filling or between root filling and } \\
\text { root canal walls }\end{array}$ \\
& $\begin{array}{c}\text { Inadequate } \\
\text { voids present in the root filling or between root filling and root } \\
\text { canal walls }\end{array}$ \\
Acceptable & $\begin{array}{c}\text { Adequate length and density } \\
\text { length of root canal filling }\end{array}$ & Adequate \\
& Over filling & Root filling ending $<2 \mathrm{~mm}$ from radiographic apex \\
& Short -filling & Root filling beyond the radiographic apex \\
& & Root filling $>2 \mathrm{~mm}$ from radiographic apex
\end{tabular}

Table 2. Distribution of teeth in maxillary and mandibular arches

\begin{tabular}{lcc}
\hline \multicolumn{1}{c}{ Tooth type } & $\mathrm{N}$ & $\%$ \\
\hline Maxillary & 87 & 44 \\
Maxillary anterior teeth & 87 & 44 \\
Mandibular & 113 & 56 \\
Mandibular anterior teeth & 1 & 0.5 \\
Mandibular premolar & 20 & 10 \\
Mandibular molars & 92 & 45.5 \\
Total & 200 & 100 \\
\hline
\end{tabular}

Table 3. Overall quality, length, and density of root canal filling

\begin{tabular}{|c|c|c|c|c|c|c|c|}
\hline \multirow{2}{*}{$\mathrm{n}$} & \multicolumn{2}{|c|}{ Quality } & \multicolumn{3}{|c|}{ Length } & \multicolumn{2}{|c|}{ Density } \\
\hline & Acceptable & Unacceptable & Adequate & Short filling & Over filling & Acceptable & unacceptable \\
\hline 200 & $90(45 \%)$ & $110(55 \%)$ & 178(89\%) & $15(7.5 \%)$ & $7(3.5 \%)$ & $69(34.5 \%)$ & 131(65.5) \\
\hline
\end{tabular}

\section{RESULTS AND DISCUSSION}

The teeth were classified according to their location in the arches. The frequencies of teeth examined in this study are shown in Table 2. There were 87 maxillary and 113 mandibular teeth. Quality of root canal filling (i.e. length, and density) is shown in Table 3. Ninety teeth (45\%) fulfilled the criteria of an acceptable root canal filling. Adequate length of the root filling was found in $89 \%$ of teeth, while $7.5 \%$ were underfilled and 3.5\% were overfilled. Adequate density was found in 34\% of teeth. The frequency of root canals with unacceptable obturation was significantly higher then the acceptable. 


\subsection{Discussion}

This study aimed to evaluate the quality of root canal treatment carried out by senior undergraduate students at Saveetha Dental College and Hospitals, Chennai. Postoperative RVG were used for assessment. The quality of root canal obturation was evaluated [16]. Studies evaluating the radiographic quality of root canal treatment have mostly been based on the evaluation of the length and the density of root canal obturation [18]-[21]. The results of this study showed that quality of root canal obturation was less than ideal. The reasons for this fact are complex and may be related to the endodontic teaching strategy undertaken at dental schools [16]. The quality of maxillary and mandibular root fillings was the same in this study. The frequency of teeth with an acceptable root canal obturation was significantly lower (45\%) compared to unacceptable (55\%) who reported that the technical quality was acceptable more often in anterior teeth. This may be explained partly by the anatomy of these teeth. The percentage of root canal fillings with adequate length was $89 \%$ in the present study. The higher percentage of overfillings reported in other studies may be attributed to the higher incidence of teeth with preexisting periapical radiolucency in these studies [10],[19],[21]. These lesions can result in resorption and destruction of the apical constriction and this loss may have influenced working length control by undergraduate students. Inadequate density of root canal obturation may lead to failure of root canal treatment because of microleakage along the root filling [20]. To sum up, in order to improve the technical quality of root canal treatment performed by undergraduate dental students, the endodontics curricula have to be revised. Thus, the time of training of the students at the clinic has to be extended, and subsequently the clinical requirements for endodontics have to be increased, so that the student will be given more time to treat more cases. The clinical training courses have to be arranged to provide the students with proper skills in endodontics.

\section{CONCLUSION}

According to the results of this observational study, the technical quality of root canal treatment performed by undergraduate dental students was found to be better on the anterior teeth compared to the posterior teeth. Thus, revision of training courses for the students at the clinic is suggested more to be given on the posterior teeth.

\section{REFERENCES}

[1] Daly R. M., Elsner R. J. F., Allen P. F., Burke F. M., “Associations between self-reported dental status and diet”, $J$. Oral Rehabil, vol/issue: 30(10), pp. 964-70, 2003.

[2] Legan J. J., Brown C. E., Jr., “Instrumentation enhances today's endodontic care”, J Indiana Dent Assoc., vol/issue: 77(4), pp. 30-4, 7-8, 40-1, 1998.

[3] Jokinen M. A., Kotilainen R., Poikkeus P., Poikkeus R., Sarkki L., “Clinical and radiographic study of pulpectomy and root canal therapy”, Scand J Dent Res., vol/issue: 86(5), pp. 366-73, 1978.

[4] Lazarski M. P., Walker W. A., Flores C. M., Schindler W. G., Hargreaves K. M., "Epidemiological evaluation of the outcomes of nonsurgical root canal treatment in a large cohort of insured dental patients", J. Endod., vol/issue: 27(12), pp. 791-6, 2001.

[5] Kerekes K., Tronstad L., "Long-term results of endodontic treatment performed with a standardized technique”, $J$ Endod, vol/issue: 5(3), pp. 83-90, 1979.

[6] Buckley M., Spangberg L. S., "The prevalence and technical quality of endodontic treatment in an American subpopulation”, Oral Surg Oral Med Oral Pathol Oral Radiol Endod, vol/issue: 79(1), pp. 92-100, 1995.

[7] Saunders W. P., Saunders E. M., Sadiq J., Cruickshank E., “Technical standard of root canal treatment in an adult Scottish subpopulation”, Br Dent J., vol/issue: 182(10), pp. 382-6, 1997.

[8] Swartz D. B., Skidmore A. E., Griffin J. A., Jr., "Twenty years of endodontic success and failure”, J Endod., vol/issue: 9(5), pp. 198-202, 1983.

[9] Smith C. S., Setchell D. J., Harty F. J., "Factors influencing the success of conventional root canal therapy-a fiveyear retrospective study”, Int Endod J., vol/issue: 26(6), pp. 321-33, 1993.

[10] Peak J. D., Hayes S. J., Bryant S. T., Dummer P. M. H., "Endodontics: The outcome of root canal treatment. A retrospective study within the armed forces (Royal Air Force)”, Br Dent J., vol/issue: 190(3), pp. 140-4, 2001.

[11] Lin L. M., Pascon E. A., Skribner J., Gangler P., Langeland K., "Clinical, radiographic, and histologic study of endodontic treatment failures”, Oral Surg Oral Med Oral Pathol., vol/issue: 71(5), pp. 603-11, 1991.

[12] Lin L. M., Skribner J. E., Gaengler P., "Factors associated with endodontic treatment failures”, J Endod., vol/issue: 18(12), pp. 625-7, 1992.

[13] Eckerbom M., Andersson J. E., Magnusson T., "Frequency and technical standard of endodontic treatment in a Swedish population”, Endod Dent Traumatol., vol/issue: 3(5), pp. 245-8, 1987.

[14] De Cleen M. J., Schuurs A. H., Wesselink P. R., Wu M. K., "Periapical status and prevalence of endodontic treatment in an adult Dutch population”, Int Endod J., vol/issue: 26(2), pp. 112-9, 1993.

[15] De Moor R. J., Hommez G. M., De Boever J. G., Delme K. I., Martens G. E., "Periapical health related to the quality of root canal treatment in a Belgian population”, Int Endod J., vol/issue: 33(2), pp. 113-20, 2000. 
[16] Barrieshi-Nusair K. M., Al-Omari M. A., Al-Hiyasat A. S., "Radiographic technical quality of root canal treatment performed by dental students at the Dental Teaching Center in Jordan”, J Dent., vol/issue: 32(4), pp. 301-7, 2004.

[17] Dummer P. M., "Comparison of undergraduate endodontic teaching programs in the United Kingdom and in some dental schools in Europe and the United States”, Int Endod J., vol/issue: 24(4), pp. 169-77, 1991.

[18] Dugas N. N., Lawrence H. P., Teplitsky P. E., Pharoah M. J., Friedman S., "Periapical health and treatment quality assessment of root-filled teeth in two Canadian populations”, Int Endod J., vol/issue: 36(3), pp. 181-92, 2003.

[19] Helminen S. E., Vehkalahti M., Kerosuo E., Murtomaa H., "Quality evaluation of process of root canal treatments performed on young adults in Finnish public oral health service”, J Dent., vol/issue: 28(4), pp. 227-32, 2000.

[20] Kirkevang L. L., Horsted-Bindslev P., Orstavik D., Wenzel A., "A comparison of the quality of root canal treatment in two Danish subpopulations examined 1974-75 and 1997-98”, Int Endod J., vol/issue: 34(8), pp. 60712, 2001.

[21] Lupi-Pegurier L., Bertrand M. F., Muller-Bolla M., Rocca J. P., Bolla M., "Periapical status, prevalence and quality of endodontic treatment in an adult French population”, Int Endod J., vol/issue: 35(8), pp. 690-7, 2002. 